\title{
Grappling with Aadhaar: Biometrics, Social Identity and the Indian State
}

\section{Silvia Masiero and S. Shakthi}

\section{(2) OpenEdition}

\section{Journals}

Electronic version

URL: https://journals.openedition.org/samaj/6279

DOI: $10.4000 /$ samaj.6279

ISSN: 1960-6060

\section{Publisher}

Association pour la recherche sur l'Asie du Sud (ARAS)

Electronic reference

Silvia Masiero and S. Shakthi, "Grappling with Aadhaar: Biometrics, Social Identity and the Indian State", South Asia Multidisciplinary Academic Journal [Online], 23 | 2020, Online since 12 mars 2020, connection on 28 juin 2022. URL: http://journals.openedition.org/samaj/6279 ; DOl: https://doi.org/ $10.4000 /$ samaj.6279

This text was automatically generated on 29 September 2020 .

\section{(†)

This work is licensed under a Creative Commons Attribution-NonCommercial-NoDerivatives 4.0 International License. 


\section{Grappling with Aadhaar: Biometrics, Social Identity and the Indian State}

Silvia Masiero and S. Shakthi

\section{AUTHOR'S NOTE}

Both authors contributed equally to this article. The authors' names are listed in alphabetical order. 
1 The Aadhaar program has been among the most defining socio-political projects of the Indian state over the last decade. Translating to "platform" or "foundation" in several Indian languages, this colossal identification scheme has been extended thus far to almost 1.25 billion Indian residents. As noted by Rao and Nair (2019), the word Aadhaar has become

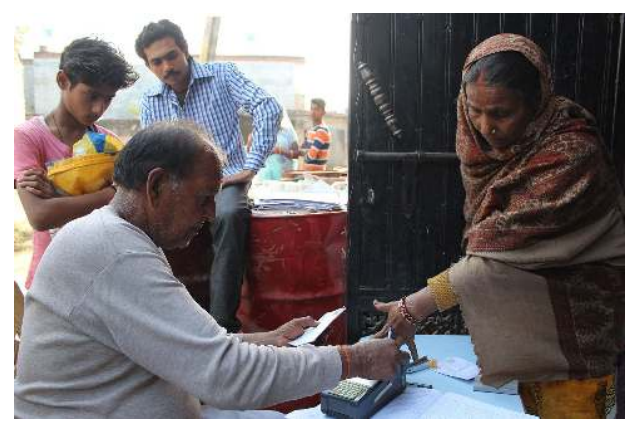
a metonymy that transcends its literal meaning, automatically linking it to the national biometric identification project that carries its name. Launched in 2010 by the newly-created Unique Identification Authority of India (UIDAI), "Aadhaar" also refers to the 12-digit unique identity number issued to residents of India upon collection of essential biometric and demographic data that are stored in a central database. UIDAI, originally an attached office of the Planning Commission (now NITI Aayog), is a statutory authority operating under the Ministry of Electronics and Information Technology; its first Chairman, Nandan Nilekani, was a co-founder of Infosys, one of India's largest information technology companies. The Aadhaar project provides an important site from which to draw broader conclusions about the marketization of the state, situated within the context of India's turn to neoliberalism in recent decades. While it places an emphasis on streamlining service delivery to marginalized residents, it also carries the potential to profoundly redefine the relationship between the state and its subjects in starkly transactional terms.

2 As the world's largest biometric identification system, Aadhaar has generated a wealth of scholarship in recent years across a number of disciplines. Much of this literature, rooted in ethnographic field research, highlights the embeddedness of Aadhaar within wider techno-social formations. In demonstrating that this biometric system can be a vital lens through which we might view the social fabric of the modern Indian nation (Rao and Greenleaf 2013), this scholarship demonstrates that Aadhaar both produces and is a product of social relations. For example, Nair (2018) has determined that the study of Aadhaar reveals the inherent instability of the very social identities it aims to control and manage. This literature also inspects surveillance as an aim and result of Aadhaar. Jacobsen (2012) has considered Aadhaar's dual role as a tool for welfare as well as surveillance, indicating that they are framed as being both mutually compatible and desirable within the wider scope of the project. Other studies have examined both theoretical (Nayar 2012) and empirically-grounded (Solanki 2019) aspects of Aadhaar as a means of legitimizing bodies, through bodies. With one of its major aims being to streamline access to welfare, an important subset of this literature considers the material realities of service provision (Chaudhuri 2019; Drèze et al 2017) and the reorientation of the state towards a market logic that views residents as consumers (Chaudhuri and König 2018). More broadly, the role of Aadhaar in carrying out various functions of the state is a crucial feature of many studies of the biometric system. This is also true of a recent Special Issue of South Asia: Journal of South Asian Studies (Rao and Nair 2019), which includes papers that cover a range of topics related to technogovernance. 
3 Much of the literature on Aadhaar indicates that the state is moving towards defining its relationship with subjects through forms of "coded citizenship". The notion of coded citizenship refers to the translation of human populations into data, resulting in the legibility of citizens as machine-readable data ensembles (Solinas 2018; Srinivasan and Johri 2014). In other words, coded citizenship can be viewed as the datafication of a population (Rao and Nair 2019), or the conversion of individuals into data for the purpose of ensuring their administrative manageability (Kitchin 2016; Taylor and Broeders 2015). This process results in the unprecedented translating into data of several aspects of society (Cukier and Mayer-Schonberger 2013:29). Simultaneously, coded citizenship transforms a disparate population into uniquely identifiable subjects through an information system's purported ability to "de-duplicate" (Cohen 2017). The tensions that arise from this dual focus on uniqueness and on collective manageability are analyzed in this Special Issue, which presents new interventions in debates on the socio-political implications of Aadhaar.

4 Constituting biopolitical technologies of rule (Rose 1999), coded citizenship can be viewed as the digitalization of a process that has been ongoing for many decades and has evolved over time (Ramanathan 2014; Rao and Greenleaf 2013). Yet, digitalization also invites a number of questions that pre-digital processes alone did not raise, which are addressed through this Special Issue in various ways. First, questions emerge around technical aspects, such as how the conversion of populations into data is conducted and the governance principles from which it is informed. Second, digitalization invites questions of a broader sociotechnical nature; datafying populations generates dichotomies between subjects who receive entitlements (leading to their "rematerialization," as Nayar [2012] has argued), and subjects to whom these entitlements are denied. This leads us to further investigate the consequences of datafication for different socio-economic groups, geographical variations in policy implementation (or, in other words, the politics of "place"), and the underlying political agendas that inform these datafication schemes.

5 These questions were first explored in a panel on "Coded Citizenship: Biometrics, Identity and De-socializing Technologies in South Asia" convened at the European Conference on South Asian Studies (ECSAS) 2018 and organized by Pier Giorgio Solinas (University of Siena). The conversations that emerged there continued beyond the conference, resulting in several thematic discussions to which colleagues from different disciplines have contributed. These discussions have resulted in this SAMAJ/ EASAS Special Issue, which, as with the conference panel, is centered on the idea of coded citizenship as a datafying phenomenon. Yet, in the one-year evolution from the initial conversations among the panelists, the central focus of this discussion has moved from a state-citizen vision (on which the original call for panel contributions was predicated) to a more holistic view of technology as a socio-political formation.

6 Traveling beyond "coded citizenship," then, the papers in this Special Issue present commentaries on technology-mediated identities more broadly, through the consideration of three perspectives on Aadhaar. Together, these three perspectives allow us to examine the interface between society and technology in constructing situated forms of modernity that are simultaneously new and contiguous with prior formations. It should be noted here that the topic set for the panel-coded citizenship, and its implications for biometric governance-was not restricted to either a particular technology or a specific geographical location within South Asia. Yet, this Special Issue 
comprises four papers that, from different angles, all investigate the role of Aadhaar in the Indian socio-political context. The common focus on Aadhaar reveals the significance of this technology for (re)shaping both social relations and modern forms of governance.

7 However, herein lies an important caveat: the thematic commonalities across the papers do not imply that Aadhaar is the only, or the main, technology of digital identification that deserves discussion. The ECSAS 2018 panel brought to light the coexistence of identification technologies within India, with the National Register of Citizens (NRC) being intertwined with dynamics of exclusion and inclusion that deeply impact the lives of residents (cf. Masiero 2019; Singh 2019). The National Database and Registration Authority (NADRA) of Pakistan also featured in the ECSAS panel discussion, and its commonalities with Aadhaar-as well as differences in terms of project genesis and goals-generated considerations of a comparative nature. The arguments made in this Special Issue, and the perspectives proposed in this introductory piece, present new insights into technology-mediated social identities in India. It is hoped that the ideas presented in this Special Issue can be used to explore new technologies of human legibility in other geographical settings, their utilization in converting populations into machine-readable data, and the individualities of the subjects they are meant to govern, categorize and manage.

\section{Aadhaar. Datafying Identity in India}

8 This Special Issue approaches Aadhaar through a set of concepts that considers the multiple meanings of coded citizenship. The four papers presented herein move beyond the singular sociotechnical view of Aadhaar as a state-citizen mediator. They investigate the evolution of governance on which coded citizenship is predicated, which, as the proliferation of biometric identification schemes across the globe highlights, has implications beyond the Indian context. Together, these papers give rise to three distinct perspectives. Each of these perspectives constitutes a way to view technologies for the biometric identification of individuals, and each of them is applied to understanding Aadhaar in the papers that comprise this thematic issue. They provide a useful framework through which to inspect broader themes such as social inclusions and exclusions, how technology operates through social institutions, and the discursive formulations that are engendered by these systems. Crafted on the basis of interdisciplinary insights, the perspectives developed in this Special Issue are as follows:

\section{Aadhaar as datafier}

9 One perspective views Aadhaar in its role as a converter of individuals into machinereadable data. This is a technical vision of digital identity systems as routes to datafication, which sees the database as the core instrument through which the conversion into data is enacted. In the view of Aadhaar as datafier, technology has the task of translating the enrolled resident-her entitlements, and what the system knows about her-into data to be utilized for administration (Masiero and Das 2019). This technical process enables two operations: the automated recognition of entitled beneficiaries of services and programs, and the assignation of entitlements based on 
what the system knows about them, as, for example, in Aadhaar-seeded programs of social protection, where identities are matched with entitlements (Chaudhuri 2019; Rao 2019).

\section{Aadhaar as platform}

10 Aadhaar as a platform on which an entire system of services is constructed. As noted by Tilson, Sørensen and Lyytinen (2013:4626), the term "platform" itself originates from " plat, meaning flat or level, and forme, meaning shape or arrangement of parts." Together the two terms imply a "flat, possibly raised surface onto which something can be placed" (Tilson, Sørensen and Lyytinen 2013:4626), suggesting that a platform is fundamentally a foundation on which to build. This perspective effectively conceives of Aadhaar as an entity composed of a central core and a set of services (complements) built on it. In the case of Aadhaar, the platform core is the database (Central Identities Data Repository) in which all enrolled residents' data are stored, and on which all Aadhaarenabled services are developed. The view of Aadhaar as platform calls for a discussion of the generativity (Zittrain 2008) of the platform itself, a property that enables unfiltered contributions without requiring input from the platform originators, resulting in the complex system of services built on the basis of Aadhaar authentication.

\section{Aadhaar as mediated surveillance}

11 The idea of biometric technology as a digital panopticon (Krishna 2019) is wellestablished in studies of Aadhaar, making surveillance a useful lens through which to study digital identification systems (Khera 2019; Rao and Nair 2019). However, the idea of surveillance mediated by Aadhaar's complements-the technologies built on top of the platform-is newer, as it moves the agent of surveillance from the platform owner (UIDAI) to all the agencies that can access and use the data stored in the database. This changes the architecture of surveillance, moving it from centralized to distributed. Thus, any entity with access to such data, both public (such as providers of social protection schemes-see Nayak, this Special Issue) or private, can possess surveillance power. Moreover, as Shakthi (this Special Issue) highlights, platform owners, and by extension, the tools for surveillance, have themselves become distributed into the private sphere. This leads to a conception of a new type of surveillance, based on both access to, and ownership of, critical data.

12 The papers in this Special Issue, with their different, yet overlapping goals, present a wider view of Aadhaar that encompasses the three perspectives outlined above. While focusing on Aadhaar, these papers move beyond the database to demonstrate how Aadhaar, and by extension technology itself, is an inherently socio-political construction. As a result, the issues of coded citizenship, technology-mediated identities and datafication as a social process constitute the focus of this collection.

While reading this Special Issue, two points must be kept in mind. First, the three perspectives proposed here-Aadhaar as a datafier of citizens, a platform for services, and an enabler of mediated surveillance-offer an integrative, rather than mutually exclusive, way of examining the same technology. While all three can be applied to a

South Asia Multidisciplinary Academic Journal, 23 | 2020 
vision of identification systems as state-citizen mediators, they are also representative of broader techno-social formations. Each of the four papers in the Special Issue provides a different combination of these perspectives, foregrounding some while implicitly commenting on others, thereby illuminating particular aspects of Aadhaar. Collectively they demonstrate that, to understand datafied systems for identification, it is important to integrate different methodological and epistemological approaches.

Second, Aadhaar should not be considered in isolation, but as part of the broader ecosystem in which it is inscribed. In the central government's Economic Survey 2014-2015, two new technologies were featured: the first was the Pradhan Mantri Jan Dhan Yojana (commonly referred to as Jan Dhan Yojana), a financial inclusion program that offers zero-balance bank accounts to low-income households (Kaur and Singh 2015); the second was mobile devices, whose ownership has increased at very high rates over the last two decades. What emerged, referred to as JAM Trinity (an acronym for Jan Dhan Yojana, Aadhaar and mobile phones), is the ecosystem in which Aadhaar operates. This positions the platform as part of a grand design of digital financialization (Jain and Gabor 2020) that affects entitlement distributions (Nayak, this Special Issue) and the architecture of the national social protection system (Masiero, this Special Issue). Similarly, the multiple legal challenges to the validity of Aadhaar since its inception, and the recent Supreme Court verdict on its very constitutionality, highlight its complex relationship with other socio-political institutions (Rao and Nair 2019). This collection emphasizes that Aadhaar is part of a broader sociotechnical environment that deeply influences public governance and people's lived experience through its workings.

\section{Papers in this Special Issue}

The threefold taxonomy of perspectives outlined above offers a way to study technology-mediated identities through the framework of Aadhaar. Below we use our taxonomy of perspectives to introduce the four papers that comprise this collection.

In the first paper, Biswarup Sen argues that the conception of the Aadhaar project underpins the turn of the Indian state to an informational model of society, revealing the rationale of using digital technologies in the service of public governance. Highlighting that this informational model is the byproduct of a long history, Sen traces the core phases of datafying technologies from colonial India to the present, demonstrating a line of continuity between colonial technologies of rule and the present scheme for biometric identification. Through this historical perspective, Sen traces how information becomes what he terms a "state good," strongly centralized on the one hand, but also flexible-and generative-in the unfiltered contributions that the platform core allows. Presenting Aadhaar as byproduct of a precise historical evolution, Sen's paper infuses new meaning into the notion of "technologies of rule" at the root of the debate on coded citizenship in postcolonial nations.

In the second paper, Nandini Nayak adopts a socio-legal perspective to highlight the advent of rights-based approaches to development management that have acquired prominence in India as well as in the formulation of anti-poverty policies on a global scale. She focuses on the development of laws that have created new legal rights, and details the principles of the universality of fundamental rights on which the National Food Security Act (NFSA) was developed, along with the right-to-food mobilization that 
became intertwined with it. Against the backdrop of the right-to-food movement, Nayak's paper frames Aadhaar as a datafier that, while enabling possibilities for better governance of food security schemes, effectively results in exclusion errors that prevent the actualization of right-to-food affordances. This tension between the imagining of universal rights, the strategies used to achieve them, and the social realities that might inhibit their efficacy is a central feature of her analysis. With her conception of Aadhaar as platform for provision of food security schemes such as the Public Distribution System (PDS), Nayak illustrates the transformational effect of Aadhaar on program governance, as well as on people's ability to access the entitlements offered by the rights-based approach of the NFSA.

In the third paper, S. Shakthi examines the prevalent framing of biometric identification technologies as a tool for combating "fraud." Moving away from a purely state-citizen perspective, Shakthi focuses on NASSCOM, the Indian IT industry employers' association, and its creation of a unique identification database (the National Skills Registry-NSR) for the verification of IT employees. Drawing on her fieldwork on the NSR in Chennai's IT industry, she interrogates the discursive construction of employee "integrity" prevalent in the industry to illustrate the forms of self-disciplining that the mere existence of such a database can entail. The paper provides a comparative framework through which to study Aadhaar's implications for individual privacy. In observing the affordances of biometric systems for mediated surveillance outside the state-citizen context, it also sheds light on the particular ways in which state-managed biometric strategies might operate as population management devices.

In the final paper, Silvia Masiero reflects on her nine-year research on the transformation of India's PDS, enacted by digital technologies first and more recently by Aadhaar's infrastructure. Based on her fieldwork on the biometric PDS in Kerala and Karnataka, she illustrates the effects of the transition to an Aadhaar-based PDS, both on the governance of the scheme and on the entitlements of recipients. Emphasizing the connections between the datafier and platform perspectives of techno-social frameworks, she highlights the persistence of exclusion errors in the scheme, and the teleology of policy change (from subsidies to cash transfers) underlying the incorporation of Aadhaar into a transformed PDS. The paper concludes the Special Issue's reflections on the transformative power of biometric infrastructures, while also considering different ways for a computerized PDS to become centered on inclusion.

As a final note, Aadhaar is frequently referred to as a blueprint for the design of biometric architectures around the globe, whose consequences in developing nations have received attention in academic research (Masiero and Prakash 2019). In opening this collection of papers, we therefore re-emphasize how Aadhaar has become a metonymy for a way of governing, and for a development rationality in which data is an instrument for the inclusive provision of public services. By extension, we consider the use of data to categorize targeted populations and the various manifestations of these processes. Similarly, trade-offs between attempts to remake the government's image through Aadhaar and the issues experienced by datafied residents are a recurring theme in this collection, which calls for investigations into other instances in which biometrics and the search for "development" are connected. Through its indepth study of a technology which has served as a model for many others, this Special 
Issue offers a way of approaching the debate on the multiple linkages between biometrics, socio-economic development and technology-mediated citizenship.

\section{BIBLIOGRAPHY}

Chaudhuri, Bidisha. 2019. "Paradoxes of Intermediation in Aadhaar: Human Making of a Digital Infrastructure." South Asia: Journal of South Asian Studies 42(3):572-87.

Chaudhuri, Bidisha and Lion König. 2018. "The Aadhaar Scheme: A Cornerstone of a New Citizenship Regime in India?" Contemporary South Asia 26(2):127-42.

Cohen, Lawrence. 2017. “Duplicate.” South Asia: Journal of South Asian Studies 40(2):301-4.

Cukier, Kenneth and Viktor Mayer-Schoenberger. 2013. "The Rise of Big Data: How It's Changing the Way We Think About the World." Foreign Affairs 92:28-36.

Drèze, Jean, Nazar Khalid, Reetika Khera and Anmol Somanchi. 2017. "Pain Without Gain? Aadhaar and Food Security in Jharkhand." Economic and Political Weekly 52(50):50-60.

Kaur, Harpreet and Kawal Nain Singh. 2015. "Pradhan Mantri Jan Dhan Yojana (PMJDY): A Leap Towards Financial Inclusion in India." International Journal of Emerging Research in Management \&Technology 4(1):25-9.

Khera, Reetika. 2019. Dissent on Aadhaar: Big Data Meets Big Brother. Hyderabad: Orient BlackSwan. Khera, Reetika. 2018. “The Aadhaar Debate: Where are the Sociologists?" Contributions to Indian Sociology 52(3):336-42.

Kitchin, Rob. 2016. The Data Revolution: Big Data, Open Data, Data Infrastructures and Their Consequences. London: Sage.

Krishna, Shyam. 2019. “Identity, Transparency and Other Visibilities: A Liquid Surveillance Perspective of Biometric Identity." Paper presented at the Development Studies Association Conference, Milton Keynes, 18-21 June 2019.

Jacobsen, Elida K.U. 2012. "Unique Identification: Inclusion and Surveillance in the Indian Biometric Assemblage." Security Dialogue 43(5):457-74.

Jain, Sudeep and Daniela Gabor. 2020. "The Rise of Digital Financialisation: The Case of India." New Political Economy, in press.

Masiero, Silvia. 2019. “A New Layer of Exclusion? Assam, Aadhaar, and the NRC.” SouthAsia@LSE, September 12. Retrieved November 16, 2019 (https://blogs.lse.ac.uk/southasia/2019/09/12/anew-layer-of-exclusion-assam-aadhaar-and-the-nrc/).

Masiero, Silvia and Amit Prakash. 2019. "ICT in Social Protection Schemes: Deinstitutionalising Subsidy-based Welfare Programmes." Information Technology \& People, in press.

Masiero, Silvia and Soumyo Das. 2019. "Datafying Anti-poverty Programmes: Implications for Data Justice." Information, Communications \& Society 22(7):916-33.

Nair, Vijayanka. 2018. “An Eye for an I: Recording Biometrics and Reconsidering Identity in Postcolonial India." Contemporary South Asia 26(2):143-56. 
Nayar, Pramod K. 2012. “'I Sing the Body Biometric': Surveillance and Biological Citizenship." Economic and Political Weekly 47(32):17-22.

Ramanathan, Usha. 2014. "Biometrics Use for Social Protection Programmes in India Violating Human Rights of the Poor." United Nations Research Institute for Social Development, May 2. Retrieved November 18, 2019 (http://www.unrisd.org/sp-hr-ramanathan).

Rao, Ursula. 2019. “Population Meets Database: Aligning Personal, Documentary and Digital Identity in Aadhaar-enabled India." South Asia: Journal of South Asian Studies 42(3):537-53.

Rao, Ursula and Graham Greenleaf. 2013. "Subverting ID from Above and Below: The Uncertain Shaping of India's New Instrument of e-Governance." Surveillance \& Society 4(1):223-34.

Rao, Ursula and Vijayanka Nair. 2019. “Aadhaar: Governing with Biometrics.” South Asia: Journal of South Asian Studies 42(3):469-81.

Rose, Nikolas. 1999. Powers of Freedom: Reframing Political Thought. Cambridge: Cambridge University Press.

Singh, Ranjit. 2019. "Give Me a Database and I Will Raise the Nation-state." South Asia: Journal of South Asian Studies 42(3):501-18.

Solanki, Aakash. 2019. "Management of Performance and Performance of Management: Getting to Work on Time in the Indian Bureaucracy." South Asia: Journal of South Asian Studies 42(3):588605.

Solinas, Pier Giorgio. 2018. "Uniqueness, Ubiquity, Authenticity: The Expanding Demosphere of the Egos." Panel foreword, European Conference of South Asian Studies (ECSAS) Conference, Paris, 23-26 July 2018.

Srinivasan, Janaki and Aditya Johri. 2013. "Creating Machine Readable Men: Legitimizing the 'Aadhaar' Mega e-Infrastructure Project in India." In Proceedings of the Sixth International Conference on Information and Communication Technologies and Development: Full Papers-Volume 1. ACM.

Taylor, Linnet and Dennis Broeders. 2015. "In the Name of Development: Power, Profit and the datafication of the Global South." Geoforum 64:229-37.

Tilson, David, Carsten Sørensen and Kalle Lyytinen. 2013. "Platform Complexity: Lessons From the Music Industry.” Pp 4625-34 in 2013 46th Hawaii International Conference on System Sciences. IEEE. Zittrain, Jonathan. 2008. The Future of the Internet and How to Stop It. New York: Yale University Press.

INDEX

Keywords: Aadhaar, biometrics, social identity, India, governance

\section{AUTHORS}

\section{SILVIA MASIERO}

School of Business and Economics, Loughborough University 


\section{S. SHAKTHI}

Department of Humanities and Social Sciences, Indian Institute of Technology Madras 